\title{
Clinical Profile of Febrile Seizure in Children: A Study in a Tertiary Care Hospital, Dhaka, Bangladesh
}

\author{
Md. Nurul Absar ${ }^{1 *}$, Sahedul Islam Bhuiyan ${ }^{2}$, Farhana Akhter Faruque ${ }^{3}$, Md. Abu Talha ${ }^{4}$
}

\author{
${ }^{1}$ Medical officer, Department of Paediatrics, Feni Sadar Hospital, Feni, Bangladesh \\ ${ }^{2}$ Professor, Department of Respiratory Medicine, Brahmanbaria Medical College, Brahmanbaria, Bangladesh \\ ${ }^{3}$ Junior consultant (Paediatrics), Naogaon Sadar Hospital, Naogaon, Bangladesh \\ ${ }^{4}$ Specialist (Pediatrics), Department of Paediatric and Neonatology, Bangladesh Specialized Hospital Ltd, Dhaka, Bangladesh
}

\author{
DOI: $10.36347 /$ sjams.2020.v08i11.048
}

| Received: 09.11.2020 | Accepted: 26.11.2020 | Published: 30.11.2020

*Corresponding author: Dr. Md Nurul Absar

Abstract

Introduction: Febrile seizures are one of the common neurological problems encountered in pediatric practice and common cause of convulsions in young infants. Seizure was diagnosed by sudden alteration of behavior with abnormal movement of limbs, trunk, and face that might be associated with abnormal or fixed eye gaze with or without incontinence of urine or stool. In USA, South America and Western Europe between 2\% and 5\% of all children experience febrile seizure before 5 years. Aim of the study: To evaluate the clinical profile and investigations of febrile seizure in children. Material \& Methods: This cross sectional study was conducted in Uttara Adhunic medical college hospital, Uttara, Dhaka, Bangladesh. The study was done in 6 months' duration $\left(1^{\text {st }}\right.$ November 2010 to $3 \mathrm{o}^{\text {th }}$ April 2011), on the children of febrile seizure. Hundred (100) patients fulfilling inclusion and exclusion criteria were selected for this study. Data recorded in questionnaires forms into computer and analyzed by using SPSS-15.0 statistical software employing appropriate statistical test and determination of $\mathrm{p}$ value. This study was approved by Ethical Committee of the BCPS. Moreover, this study was done following the guideline of BMRC (Bangladesh Medical Research Council). Results: In this study, age distribution of the patients $(\mathrm{n}=100)$ were divided into three age groups. Incidence was most common in 1-2 years' age group (43\%), slightly lower in 5 months -1-year group (39\%) and incidence declined sharply in 2-6 years' age group which was $18 \%$. Male to female ratio was $1.27: 1$. Ninety-two (92\%) febrile seizures were of less than 15 minutes' duration, 95\% generalized, and single attack of seizure in $89 \%$ cases, incidence of 2 attack in $7 \%$ and more than 2 in $4 \%$ cases. Conclusion: Family history was positives in significant number of cases. No significant association found between this disease and any antenatal, natal, post-natal or childhood adverse events.

Keywords: Febrile Seizure, Neurological, Convulsion, Fever, Diagnostic, Investigations.

Copyright $\odot 2020$ The Author(s): This is an open-access article distributed under the terms of the Creative Commons Attribution 4.0 International License (CC BY-NC 4.0) which permits unrestricted use, distribution, and reproduction in any medium for non-commercial use provided the original author and source are credited.

\section{INTRODUCTION}

Febrile seizures have been discussed in the medical literature since the time of Hippocrates, but it was not until the middle of the present century that they were recognized as a separate syndrome distinct from epilepsy [1]. Febrile seizures are one of the common neurological problems encountered in pediatric practice and common cause of convulsions in young infants. Seizure was diagnosed by sudden alteration of behavior with abnormal movement of limbs, trunk, and face that might be associated with abnormal or fixed eye gaze with or without incontinence of urine or stool. It has come out as a debated issue due to controversies in its definition, classification, diagnostic interventions, and management [2]. It occurs between 6 months to 6 years of age. As defined in National Institutes of Health consensus conference (by American academy of pediatrics) a febrile seizure is: "An event in infancy or early childhood, usually occurring between three months and five years of age, associated with fever but without evidence of intracranial infection or defined cause." Febrile seizures are classified as either simple or complex. Simple febrile seizures consist of a brief (lasting less than 10 minutes) tonic-colonic convulsion which occurs only once within a 24 -hour period. There are no focal features and it resolves spontaneously. Conversely, complex febrile seizures are prolonged (greater than 10-15 minutes), focal, or multiple (recurrent within the same febrile illness over a 24-hour period). While the majority of febrile seizures are simple (70-75\%), 9-35\% of febrile seizures are complex [3]. Majority of febrile convulsions occurred in first two years of life. The incidence is slightly higher in boys than in girls, but they tend to occur earlier in girls [4]. 
Family history of febrile seizure is present in $23 \%$ cases that is there is very high familial incidence. Variation in prevalence relates to differences in case definitions, ascertainment methods, geographical variation, and cultural factors [5]. In USA, South America and Western Europe between $2 \%$ and $5 \%$ of all children experience febrile seizure before 5 years. Estimates of frequency of febrile seizure are much higher in Japan $(8 \%)$ and Mariana Island (15\%) [6]. Incidence of febrile seizure is $3-4 \%$ but varies according to geographical and ethnic distribution. As of symptoms, most of respiratory system origin followed by nonspecific, gastrointestinal and origin in chronological order. UTI patients had only symptoms but no signs. Febrile seizure is one of the leading causes of doctor consultation on emergency basis and hospital admission in pediatric age group; parent's become greatly panicked by the expression of the disease and also remains anxious about the prognosis of this benign disease, and clinical profile is important for appropriate diagnosis, hence better management and also for parent counseling. A clear understanding of febrile seizure would help doctors to refine clinical judgment in diagnosing and managing the case.

\section{Methodology And Materials}

This cross sectional study was conducted in Uttara Adhunic medical college hospital, Uttara, Dhaka. The study was done in 6 months' duration $\left(1^{\text {st }}\right.$ November 2010 to $3 \mathrm{o}^{\text {th }}$ April 2011.), on the children of febrile seizure. Hundred (100) patients fulfilling inclusion and exclusion criteria were selected for this study. Seizure was diagnosed as complex if- 1) it was prolonged (more than 15 minute); 2) if it had multiple convulsion in the same episode of illness (more than 2) and; 3) if the seizure was focal or multifocal. Associated illness was diagnosis on the basis of system specific complaints, positive examination findings and relevant investigation. 'Fever without source' diagnosed if there was no system specific complaint, examination finding and normal investigation findings. All the diagnosis, classification and investigations were done under supervision of consultant paediatrician. After enrollment in the study a through history taken to have a clue to the diagnosis and associated illness. Careful physical examination done for each patient and investigation was advised according to suspicion of differential diagnosis, associated illness or complication, all findings was recorded in a predesigned questionnaire. Data was collected and other information including investigation results was entered. Data were analyzed by using SPSS-15.0 statistical software employing appropriate statistical test and determination of $\mathrm{p}$ value. This study was approved by Ethical Committee of the BCPS. Moreover, this study was done following the guideline of BMRC (Bangladesh Medical Research Council).
Inclusion Criteria:

- Age more than 5 months and less than 6 years.

- Fever with convulsion

\section{Exclusion Criteria}

- Age less than 5 months and more than 6 years.

- Previous afebrile seizure.

- Children with neurologic deficit with febrile seizure.

- Patients presented with meningitis or encephalitis

- Patients presented with Hyponatremia, Hypernatremia, hypocalcaemia, and Hypoglycemia

\section{RESUltS}

In this study, age distribution of the patients $(n=100)$ were divided into three age groups. Incidence was most common in 1-2 years' age group was $43 \%$, slightly lower in 5 months -1-year group (39\%) and incidence declined sharply in 2-6 years' age group which is $18 \%$ (Figure-1). Statistical analysis of patients of both sex showed that boys $(56 \%)$ were slightly more affected than girls $(44 \%)$. Male to female ratio was 1.27:1 (Figure-2). Figure 3, 4 and 5 shows 92\% febrile seizures were of less than 15 minutes' duration, $95 \%$ generalized, and single attack of seizure in $89 \%$ cases, incidence of 2 attack in $7 \%$ and more than 2 in $4 \%$ cases. First febrile seizure attack in most of the cases took place in 1-2 years' age group (47\%) followed by 5 months-1-year age group (32\%) and fewer in older age group in $2-6$ years $(21 \%)$. P value was 0.001 at confidence interval of $95 \%$ (i.e. significant.) for 1-2 years' age in related to other age group. However, $\mathrm{P}>$ 0.005 for other age groups (Figure-6). Family history of febrile seizure was present in $23 \%$ cases. $P$ value was 0.001 at confidence interval of 95\% (Figure-7) Temperature was not recorded in most of the cases $(83 \%)$, of those recorded, more of high grade $(9 \%)$, less of low grade $(7 \%)$, and very few of very high grade (1\%), $\mathrm{P}$ value was $0.602,0.502$ and 0.7 accordingly with confidence interval $95 \%$ (Table-1). History of adverse antenatal, natal and post-natal event was present in 5\%, 3\%, and 3\% cases respectively that were statistically not significant (Table-2). Those were statistically not significant (Table-3). Presenting symptoms, with fever and seizure was observed in all the cases $(100 \%)$. Most presented with respiratory complaints followed by nonspecific symptoms, gastrointestinal and urinary system in chronological order (Table-4). Table-5 Shows presenting signs. As of symptoms, most of respiratory system origin followed by nonspecific, gastrointestinal and origin in chronological order. UTI patients had only symptoms but no signs. Maximum (62\%) children presented with acute respiratory tract infection as the cause of fever, $18 \%$ due to acute gastroenteritis $6 \%$ for urinary tract infection. In addition, the cause of fever could not be determined in remaining $14 \%$ children (Figure-8). 
Previous history of febrile seizure and new incidence of the illness that there is high recurrence rate of the illness. $p=0.001$ at confidence interval of $95 \%$ (Figure9).

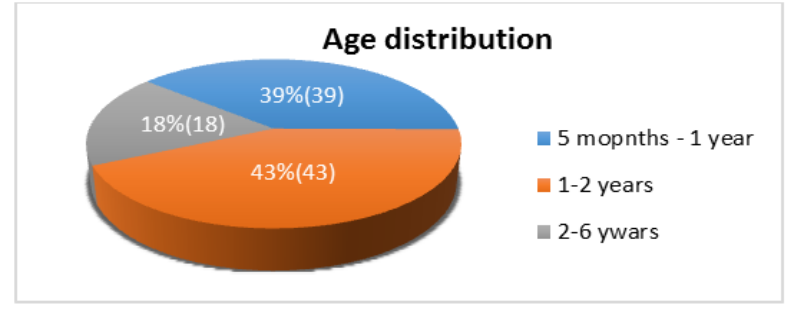

Fig-1: Pie chart illustrating Age distribution of the patients $(\mathbf{n}=\mathbf{1 0 0})$

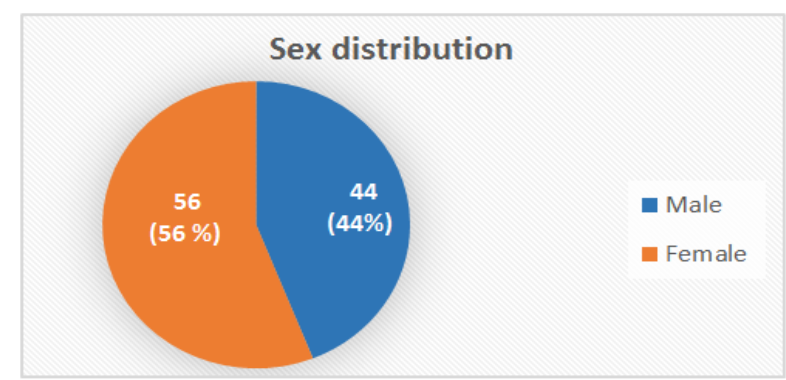

Fig-2: Pie chart illustrating sex distribution of the patients $(\mathbf{n}=\mathbf{1 0 0})$

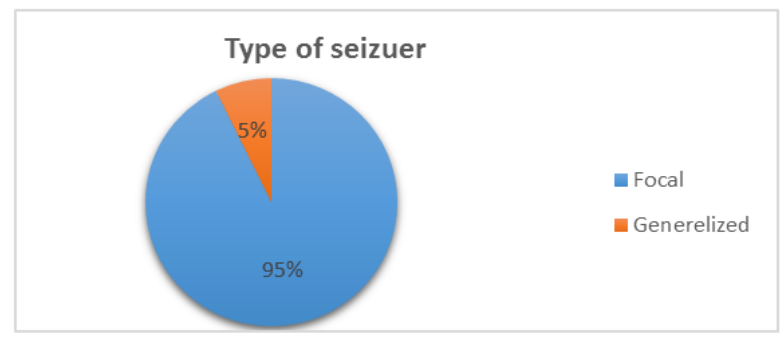

Fig-3: Pie chart illustrating type of seizure $(n=100)$

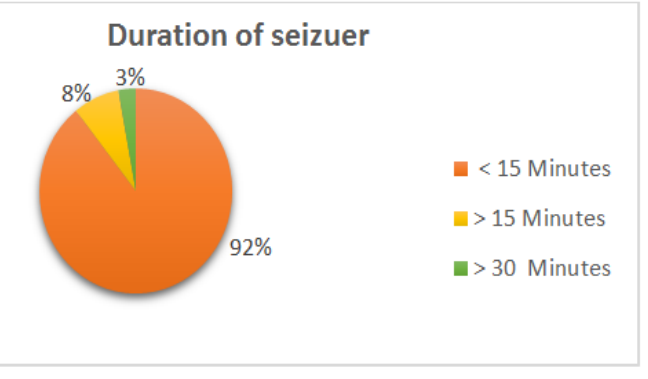

Fig-4: Pie chart illustrating duration of seizure $(n=100)$

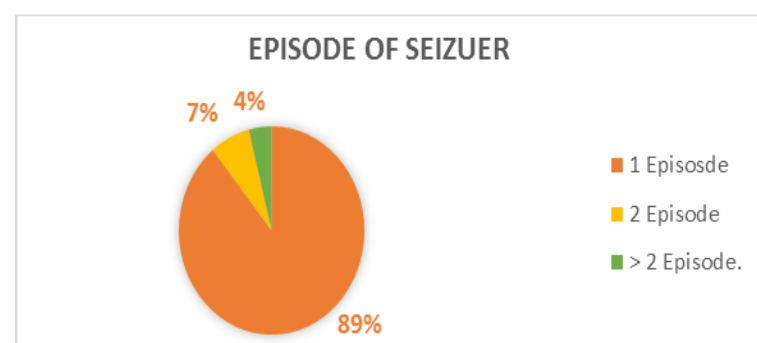

Fig-5: Pie chart illustrating episode of seizure $(n=100)$

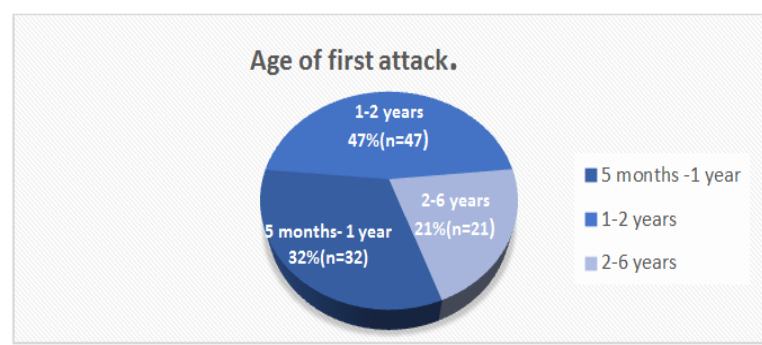

Fig-6: Pie chart illustrating Age of first episode of febrile seizure $(n=100)$

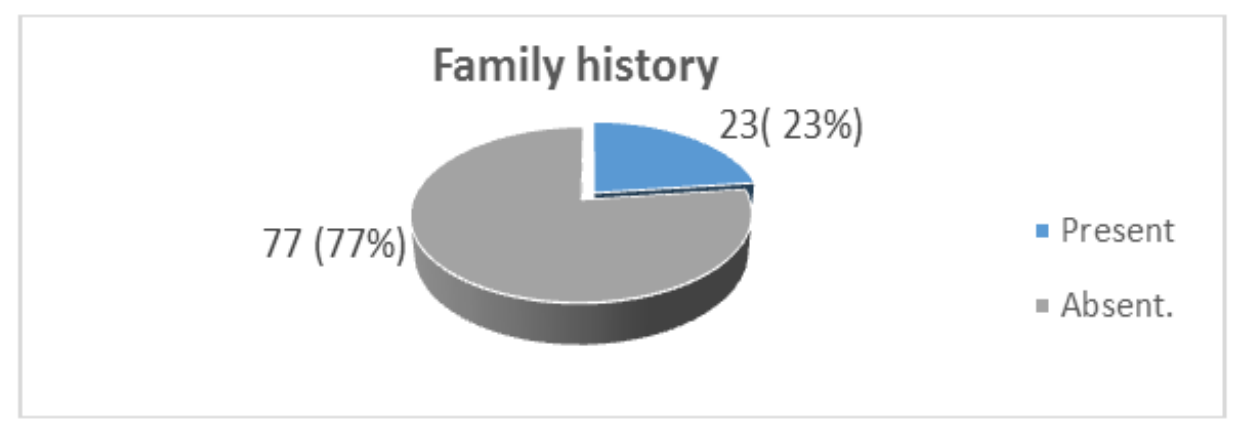

Fig-7: Pie chart showing family history of febrile seizure (n=100)

Table-1: Relation of Seizure with degree of fever

\begin{tabular}{|l|l|l|}
\hline Seizure attack at degree fever & Number & Percentage $(\%)$ p value \\
\hline Low grade $\left(<103^{0} \mathrm{~F}\right)$ & 7 & $7>.005^{\mathrm{NS}}$ \\
\hline High grade $\left(103^{0}-107^{0} \mathrm{~F}\right)$ & 9 & $9>.005^{\mathrm{NS}}$ \\
\hline Very high grade $\left(>107^{0} \mathrm{~F}\right)$ & 1 & $1>.005^{\mathrm{NS}}$ \\
\hline Not recorded & 83 & $83 \mathrm{NA}^{* *}$ \\
\hline $\begin{array}{l}\text { (NS }=\text { not significant }) \\
\text { (NA }=\text { not Applicable })^{* *}\end{array}$ \\
\hline
\end{tabular}


Table-2: History of any adverse antenatal, natal or immediate post-natal event

\begin{tabular}{|l|l|l|}
\hline Antenatal adverse event & Number & Percentage $(\%)$ p value \\
\hline Natal adverse event & 5 & $5>.005^{\mathrm{NS}}$ \\
\hline Immediate post-natal adverse event & 3 & $3>.005^{\mathrm{NS}}$ \\
\hline
\end{tabular}

Table-3: History of any adverse neurological event at or after birth

\begin{tabular}{|l|l|l|}
\hline Event. & Number(100) & Percentage (100\%) \\
\hline Trauma to head & 3 & 3 \\
\hline Meningoencephalitis & 2 & 2 \\
\hline Neurosurgery & 0 & 0 \\
\hline
\end{tabular}

Table-4: Presenting symptoms

\begin{tabular}{|l|l|l|}
\hline $\begin{array}{l}\text { Symptoms. } \\
\text { Number(100) }\end{array}$ & Number (100) & Percentage (\% \\
\hline Fever & 100 & 100 \\
\hline Convulsion. & 100 & 100 \\
\hline Cough or cold & 9 & 9 \\
\hline Difficulty in breathing. & 11 & 11 \\
\hline Cough or cold with Difficulty in breathing. & 21 & 21 \\
\hline Pain in the throat & 4 & 4 \\
\hline Ear ache/Discharge from ear. & 2 & 2 \\
\hline Loose stool and /or Vomiting. & 17 & 17 \\
\hline Dysuria, urgency, frequency. & 4 & 4 \\
\hline Fever and convulsion with no other systemic complaints. & 24 & 24 \\
\hline
\end{tabular}

Table-5: Presenting signs

\begin{tabular}{|l|l|l|}
\hline Signs & Number(n=100) & Percentage (100\%) \\
\hline Fever & 100 & 100 \\
\hline convulsion & 21 & 21 \\
\hline Rhinorrhea. & 19 & 19 \\
\hline Signs of respiratory distress & 30 & 30 \\
\hline Inflamed throat/tonsil. & 10 & 10 \\
\hline Purulent /serous /seropurulent Discharge from ear & 4 & 4 \\
\hline No systemic specific sign. & 26 & 26 \\
\hline
\end{tabular}

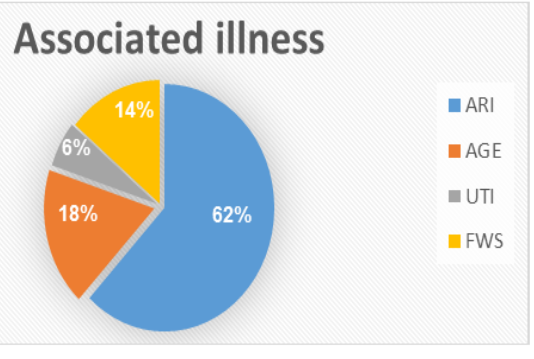

Fig-8: Associated illness

100

\section{Recurrence and new case.}

\section{$68(68 \%)$}

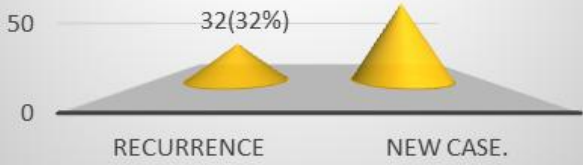

Fig-9: Bar diagram for Recurrence and new case $(\mathbf{n}=\mathbf{1 0 0})$

\section{DISCUSSION}

In this study, febrile seizures started in first year of life peak in second year and the incidence declined with increasing age. There were $39 \%$ of children below 1 year, $82 \%$ below 2 years (including $<1$ year). Study conducted by Saidulhaque in 1981 revealed that, $39.5 \%$ of cases were below 1 year and $60.5 \%$ of cases were more than 1 year [7]. In another study, $37 \%$ of children were below 16 months and 63 percent were above 16 months of age [8]. In that study male, female ratio was 1.27:1. Approximately the same result found in another study [4] but significantly higher ratio (1.62: 1) was found in children of Singapore [9]. Seizures were predominantly brief, generalized toniccolonic and a few had focal features (5\%). The observation for focal one was observed in between 4 to $16 \%$ in some studies [10-12]. Seizures lasted more than 15 minutes in $8 \%$ children in the present study. Status epilepticus (>30 minutes' duration) occurred in 5\% children in our study. In another study these were almost the same (9\% and 5\% respectively) [10]. Previous studies have shown $20 \%$ and $29 \%$ of children 
with positive family history [7, 13]. In a study conducted by Wallace in 1975 showed positive family history was also associated with decreased risk of complex febrile seizures [8]. It has been reported that in 25-42 percent of cases, seizure is the first symptom and fever appeared later [14-16]. In our study low grade was $7 \%\left(<103^{\circ} \mathrm{F}\right)$, high grade $9 \%\left(103^{0}-107^{\circ} \mathrm{F}\right)$ and very high grade was $1 \%\left(>107^{\circ} \mathrm{F}\right)$. There was no significant association between any adverse antenatal, natal or immediate post-natal events (was 5, 3 and 3 respectively) and there was also no significant association to any adverse neurological event in our study which reflects the study of Lynette G Sadleir [17]. Seizure may be the first sign of illness and may occur even before the fever is noticed [16]. It was reported that higher fever from bacterial upper respiratory infections might not cause a fit [4]. No evidence exists that febrile seizures are more likely to occur with the maximal rate of temperature rise, although this is often quoted [6]. The fraction of simple seizure was varied according to causes of fever; $84 \%$ in UTI, 93\% in FWS, $95 \%$ in ARI. In the present study, complex seizures occurred in $14 \%$ of cases and simple seizures in $86 \%$. In a study by al-Eissa et al., in 1992, 38\% were of complex seizure and $62 \%$ cases were simple [18]. However, another study has shown complex febrile seizure in $61.83 \%$ of cases [8]. Previous studies have also reported that age less than 12 months was related with increased incidence of complex febrile seizures [13, 18].

\section{Limitations of the study}

This was a single center study with small sample size. So, the findings may not be reflected in the whole community.

\section{CONCLUSION AND \\ RECOMMENDATIONS}

Family history was positives in significant number of cases. No significant association found between this disease and any antenatal, natal, post-natal or childhood adverse events. No definite conclusion could therefore be drawn from this study. So, larger scale, nationwide, longer duration study is recommended.

\section{REFERENCES}

1. Hirtz DG. Febrile seizures. Pediatrics in review. 1997 Jan 1;18:5-9.

2. Rahman MM, Karim ASMB, Rahman SA. Febrile Seizures: An Update. Bangladesh J Child health. 2002; 26 (3/4): 71-79.

3. Jones T, Steven JJ. Childhood Febrile Seizures: Overview and Implications. International Journal of Medical Sciences. ISSN 1449-1907 www.medsci.org 2007 4(2):110-114

4. Brown JK, Minns RA. Disorders of the Central Nervous System. In: Campbell AGM, McIntosh N (eds). Forfar and Arneil's Textbook of Pediatrics, 4th Ed, Churchill Living stone, Longman Group UK Ltd. 1998:682-684.

5. Kjeldsen MJ, Kyvik KO, Friis ML, Christensen K. Genetic and environmental factors in febrile seizures: a Danish population-based twin study. Epilepsy Res. 2002; 51:167-77.

6. Offringa M, Moyer VA. Evidence based management of seizures associated with fever. BMJ. 2001; 323:1111-114.

7. Saidulhaque. Febrile Convulsions. Pakistan Pediatric Journal. 1981; 5(3):15-55.

8. Wallace SJ. Factors predisposing to a complicated initial febrile convulsion. Arch Dis Child. 1975; 50:943-947.

9. Lee WL, Low PS, Belinda, Ranjan U. Epidemiology of febrile seizure in Singapore children. Neurol J South east Asia. 1996; 1:53-55.

10. Berg AT, Shinnar S, Hanser WA, Levanthal JM. Predictors of recurrent Febrile convulsions: A metaanalytic review. J Pediatr. 1998; 116: 329337.

11. Nelson KB, Ellenberg JH. Prognosis in children with febrile seizures. Pediatrics. 1978; 61: 720727.

12. Annegers JF, Hauser WA, Shirts SB, Kurland LT. Factors prognostic of unprovoked seizures after febrile convulsions. N Engl J Med. 1987; 316:4938.

13. Farwell JR, Blackner G, Sulzbacker S, Adelman L, Voller M. First febrile seizures. Characteristic of the child, the seizures, and the illness. Clin Paediatr Phila. 1994; 33(5):263-7.

14. Fukuyama Y, Seki T, Otsuka C, Miura H, Hara M. Practical guidelines for physicians in the management of febrile seizures. Brain Dev. 1996; 18: 479-484.

15. Rajadhyaksha S, Shah KN. Controversies in febrile seizures. Indian J Pediatr. 2000; 67; SS1: S71-S79.

16. Aicardi J. Febrile Convulsions. In: Aicardi J (ed). Epilepsy in Children: International Review Child Neurology. Lippin Cott- Review, 2nd ed. 1996; 252-275.

17. Sadleir LG, Scheffer IE. Febrile seizures. Bmj. 2007 Feb 8;334(7588):307-11.

18. Al- Eissa YA, Al- Omair AO, Al- Herbish AS, Al- Jarallah AA, Familusi JB. Antecedents and outcome of simple and complex febrile convulsions among Saudi children. Developmental Medicine \& Child Neurology. 1992 Dec;34(12):1085-90. 